\title{
Sliding Mode Load torque Observer based effective disturbance rejection for a 3-Phase BLDC drive
}

\author{
Jagat Jyoti Rath \\ QHS (T) \\ Drives and Controls Lab \\ CSIR-CMERI, INDIA
}

\begin{abstract}
In this work an Exponential reaching law based Sliding mode controller (SMC) controller has been proposed for the outer loop speed control of the 3-Phase Brushless DC(BLDC) motor drive. The robust hysteresis controller is employed to control the inner loop current performance of the drive. The developed SMC control scheme is simulated on MATLAB/SIMULINK platform under varying load torque disturbances up to the rated torque capability and the variable speed performance of the drive is tested. A sliding mode based load torque observer has also been designed for implementation of the scheme on real time basis. The efficient load torque rejection capabilities of the developed control scheme using the sliding mode load torque observer is then compared with a Proportional Integral (PI) based controller.
\end{abstract}

\section{General Terms}

Sliding Mode Control

\section{Keywords}

BLDC motors, Load Torque Observer, Power rate reaching law approach, Sliding Mode Control

\section{INTRODUCTION}

BLDC motors act as variable speed drives in the automation [1], aviation and modern electric vehicle industry [2]. The high torque to weight ratio, compact size and efficient performance make these motors ideal for drive applications such as in conveyer belts, fuel pump control, electric vehicle control, pneumatic device control amongst others. The controller designed for these purposes thus should be robust enough to handle any kind of disturbances that act on the system. In the case of drives employed in the industry load is the primary disturbance which continually changes subjecting the controller of the drive in use to respond to abnormal conditions. The BLDC drive is subjected to commutation by electronic means using a Voltage Source Inverter (VSI) or a Current Source Inverter (CSI) which incorporates switching along with non linearities associated in the motor design. The entire system thus behaves as a non-linear time varying discontinuous system subject to load variations. In the mechanical aspect the load is reflected as opposing torque for the motor. In load conditions the current of the motor shoots up to abnormal values resulting in excess damage to the system. The problem of load disturbance rejection has plagued the industry since long. Many types of control algorithms like Fuzzy Logic Control [3], Neural Network Control [4], Adaptive Control[4], Optimal Control[4], Particle
Swarm Optimization[5] based control along with the simplest Proportional Integral[3] control have been reported in literature for the load disturbance rejection control in case of BLDC drives. However these control techniques either failed in handling the non-linearity of the BLDC drive or were unable to give effectual performance under variable load conditions.

Sliding Mode control [6] emerged as the frontrunner in solving the problem afflicting the industry regarding load disturbance rejection as well as handling non-linearities. Since early 1990's researchers such as Utkin [6] and PC Sen [7] have led the way in establishing the fact that Sliding mode control can be used for effective disturbance rejection control of drives despite inducing high frequency oscillations into the system christened chattering.

In this work an Exponential Reaching law [8] based Sliding Mode control scheme has been developed on MATLAB/SIMULINK platform for the outer loop speed control of a 3-Phase BLDC drive. The inner loop current control of the drive is performed by the robust hysteresis control technique. The non linear 3-Phase model of the BLDC drive that detects commutation is developed and then for varying load disturbance conditions the developed controller is tested. The performance of the developed controller is compared with a PI scheme implemented for the outer speed loop. For implementation of the developed scheme on real time basis a sliding mode based load torque observer [9] has been designed. .

The work is organized as follows:

- Section 2 introduces the concept of Sliding mode control

- Section 3 provides the electromechanical model of the drive.

- In Section 4 the design of sliding mode controller and torque observer is presented.

- The results of the simulated control scheme and observer on MATLAB platform is presented in Section 5.

- The conclusion of the study is given in Section 6. 


\section{SLIDING MODE CONTROL}

Sliding Mode Control algorithm was developed in the former Soviet Union as a response to the disturbance rejection problems bothering the industry. Relying on the concepts of developing a stable attractor plane [10] and by continuous switching of the controlled variable so as to force the state trajectory onto the plane, it assumed significance as a control topology that was invariant to parametric uncertainties and was unaffected by disturbances once in the sliding mode. The design aspects of the developed non-linear control law were established using Lyapunov's Second theorem of stability [11]. With continued research in the domain the concept of reaching law approach was first proposed by Gao \& Hung [8]. The reaching law approach directly specifies the dynamics of developed sliding surface [8] in the reaching phase.

For a single input non linear system of the form

$$
x=f(x, x)+G(x, x) u+D
$$

Where, $\mathrm{D}=$ external disturbances

$\mathrm{G}=$ uncertainty in input

$u=$ control input

Then the states of the system are,

$$
X=\left[x_{1}, x_{2}, x_{3}, \ldots \ldots \ldots, x_{n}\right]
$$

The sliding surface is thus, $\sigma=C^{T} X$. Where, ' $C$ ' is the sliding surface parameter. The general representation of the reaching law approach is given as,

\section{$\bullet$}

$\sigma=-K \operatorname{sgn}(\sigma)-\varepsilon f(\sigma)$

Where the gains $\varepsilon>0, K>0$

Signum function $\operatorname{sgn}(\sigma)$ is defined as

$\operatorname{sgn}(\sigma)=\left\{\begin{array}{ll}1 & \sigma>0 \\ -1 & \sigma<0\end{array}\right\}$

Satisfying the reaching condition of sliding mode $\sigma \dot{\sigma}<0$ the control law is designed such the time taken for the reaching the sliding mode is completed very fast. The exponential reaching law is given as,

$\sigma=-K \operatorname{sgn}(\sigma)-\varepsilon \sigma$

Where the constants $K, \varepsilon$ are chosen as per the reaching time criterion given as,

$t_{\text {reach }} \leq \frac{1}{\varepsilon} \ln \left(\frac{\varepsilon\left|\sigma_{0}\right|+\eta}{\eta}\right)$
Where, $K=\frac{G|R|+D+\eta}{1-G}[11]$

$\eta=$ A positive real number, $\sigma_{0}=$ initial value of trajectory

$R=\stackrel{\bullet}{x e f-f-\varepsilon e}$

Where, $\mathrm{e}=$ desired value-actual value .

\section{BLDC MOTOR MODEL}

The 3-phase BLDC motor is electronically commutated by the use of a fast switching based 3-phase VSI (Voltage Source Inverter) instead of a mechanical commuataor. The gating sequence for these switches is provided by inner current loop control.

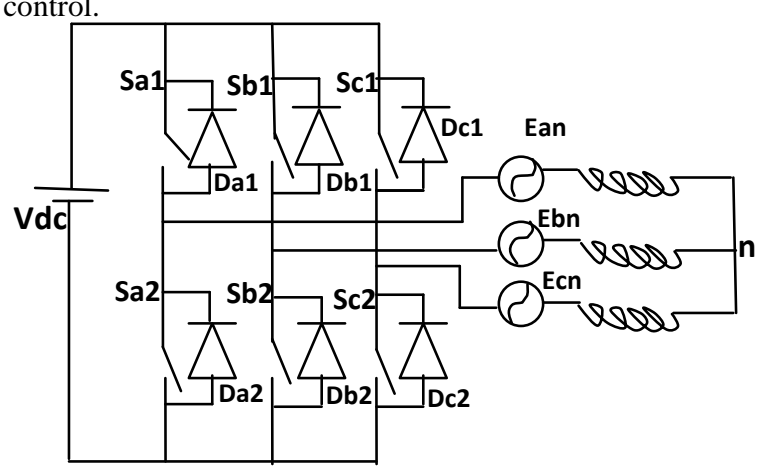

Fig 1: Schematic of the VSI fed BLDC motor

In the above figure $2, S_{x y}$ refers to the switches used while $\mathrm{D}_{\mathrm{xy}}$ refers to the protection diodes where $\mathrm{x}=$ ' $a$ ' or ' $b$ ' or ' $c$ ' while $y=$ ' 1 ' or ' 2 ' or ' 3 '.

Using KVL for phase ' $a$ '

$V_{a n}=V_{a N}+V_{n N}$

The per phase equation of the BLDC motor are then developed as follows:

$$
\begin{aligned}
& V_{a n}=R i_{a}+L \frac{d i_{a}}{d t}+E_{a n} \\
& \text { Or, } V_{a N}=i_{a} R+L \frac{d i_{a}}{d t}+E_{a N}+V_{v N}
\end{aligned}
$$

Where,

$V_{a n}=$ Per phase voltage across the winding.

$V_{a N}=$ Per phase pole voltage applied.

$V_{n N}=$ Pole to neutral voltage applied. 
$V_{d c}=\mathrm{DC}$ voltage applied in Volts.

$L=$ Inductance of the windings in Henry.

$R=$ Resistance of the windings in Ohms.

$E_{a n}=$ Per Phase Back emf of the motor.

Similar equations for each of the phases can be developed. In the BLDC drive there are basically two modes of conduction, two phase mode and three phase mode. During the two phase mode of conduction considering phases ' $a$ ' and ' $b$ ' are conducting while ' $c$ ' is floating,

$$
V_{a N}+V_{b N}-2 V_{n N}=E_{a n}+E_{b n}
$$

But since

$$
E_{a n}=-E_{b n}
$$

So, $V_{n N}=\left(V_{a N}+V_{b N}\right) / 2$

similarly during the three phase mode of conduction,

$V_{a N}+V_{b N}+V_{c N}-3 V_{n N}=E_{a n}+E_{b n}+E_{c n}$

Or, $V_{n N}=\frac{1}{3}\left[\sum V_{x N}-\sum E_{x n}\right]$

The above equations (10), (13) and (15) can be written as,

$$
\begin{gathered}
\left(\begin{array}{c}
\frac{d i_{a}}{d t} \\
\frac{d i_{b}}{d t} \\
\frac{d i_{c}}{d t}
\end{array}\right)=\left(\begin{array}{ccc}
-R / L & 0 & 0 \\
0 & -R / L & 0 \\
0 & 0 & -R / L
\end{array}\right)\left(\begin{array}{l}
i_{a} \\
i_{b} \\
i_{c}
\end{array}\right)+\frac{1}{L}\left(\begin{array}{l}
V_{a N} \\
V_{b N} \\
V_{c N}
\end{array}\right)+ \\
\frac{1}{L}\left(\begin{array}{ccc}
-E_{a n}-V_{n N} & 0 & 0 \\
0 & -E_{b n}-V_{n N} & 0 \\
0 & 0 & -E_{c n}-V_{n N}
\end{array}\right)
\end{gathered}
$$

Where, $V_{x N}=V_{d c}=$ Voltage as input.

$E_{x n}, V_{n N}=$ Disturbance input.

$x=$ Phase ' $a$ ' or ' $b$ ' or ' $c$ '

The relation between torque and speed can be obtained by the following differential equation as,

$T=J \frac{d \omega}{d t}+B \omega+T_{L}$
$T=$ Torque in Newton-meter

$J=$ Moment of inertia in $K g \cdot \mathrm{m}^{2}$

$T_{L}=$ Disturbance input.

$B=$ Coefficient of friction in $\mathrm{Kg} / \mathrm{ms}$.

The above equation in (17) can also be written as

$\frac{d \omega}{d t}=\frac{1}{J}\left(-B \omega+T-T_{L}\right)$

\section{PROPOSED ALGORITHM}

\subsection{Control Law}

As per sliding surface concept form Slotine and $\mathrm{Li}, 1991[11]$ the switching surface for a tracking problem can be expressed as, $S=\left(\alpha+\frac{d}{d t}\right)^{n-1} e$

For that, $n=$ Order of the system.

$\alpha=$ Constant

$e=$ Error signal (Reference output-actual output).

For speed control the sliding surface is developed as,

$$
\sigma=e_{\omega}=\stackrel{*}{\omega} \omega
$$

Where, $\omega=$ Desired/Reference value of current

$\omega=$ Obtained value of current.

By employing the exponential reaching law from equation (5) it can thus be written that,

$$
\dot{\sigma}=-\varepsilon \operatorname{sgn}(\sigma)-K \sigma=\frac{d e_{\omega}}{d t}=\frac{d\left(e_{\omega}-e_{\omega}\right)}{d t}
$$

Or, $\frac{d\left(e_{\omega}\right)}{d t}+\frac{B \omega-T+T_{l}}{J}=-\varepsilon \operatorname{sgn}(\sigma)-K \sigma$

Or, $T=J\left(\frac{d\left(e_{\omega}\right)}{d t}+\varepsilon \operatorname{sgn}(\sigma)+K \sigma\right)+T_{l}+B(\omega-e)$ 


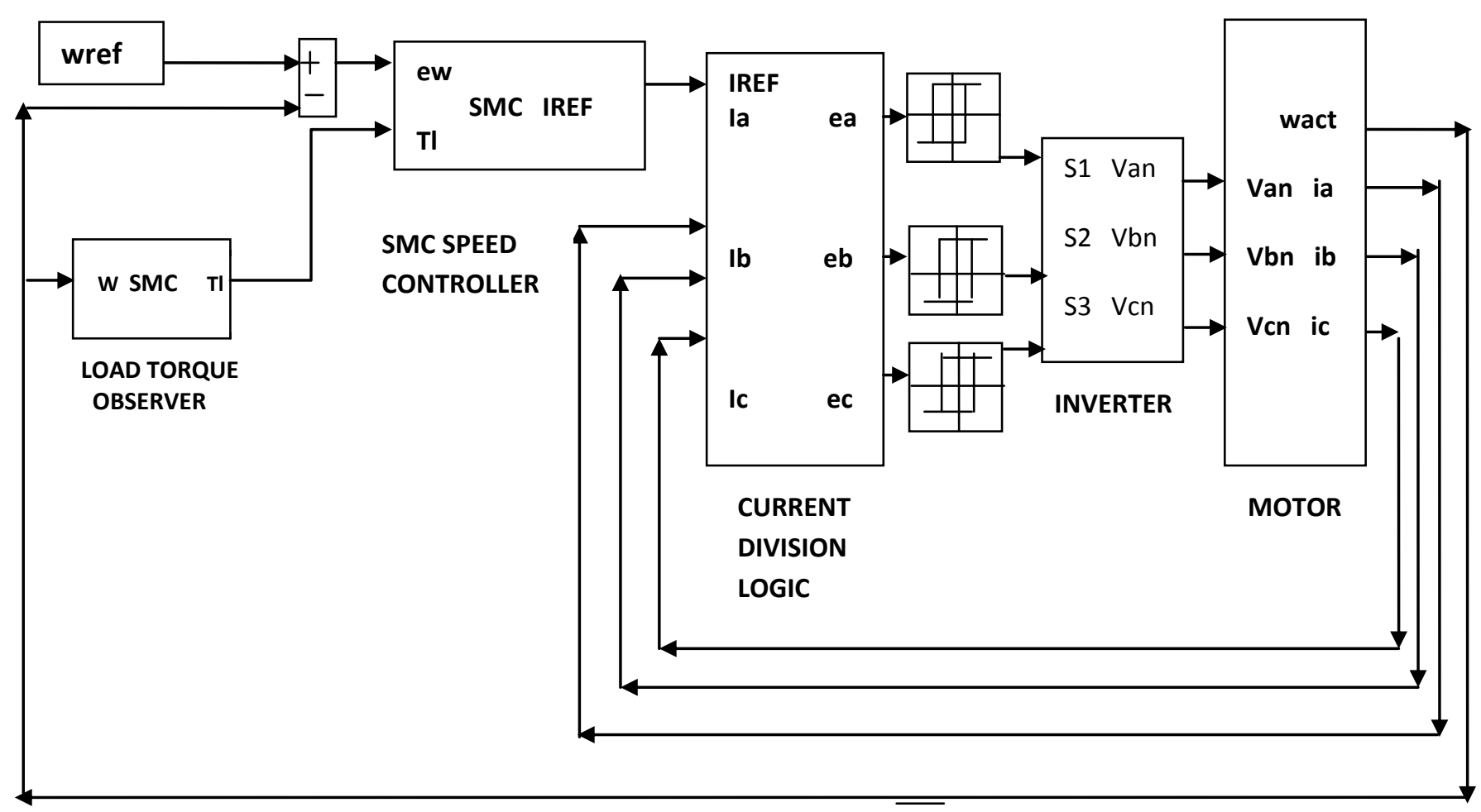

Fig 2: Schematic of the developed Controller-Observer scheme for BLDC drive

\subsection{Load Torque Observer}

In case of implementation of the control law developed in equation (23) it is necessary to feed load torque to the controller in order to generate the reference torque. However since load torque cannot be directly measured hence a sliding mode based load torque observer is designed. The sliding mode observer [12] uses non-linear high gain feedback to drive the estimated load torque onto the stable sliding mode. The observer is so designed that it is faster that the dynamics of load torque such that it can assumed that $\frac{d T_{l}}{d t}=0$. Using $T_{l}$ as an extra state variable the augmented equations can be written as,

$\left(\begin{array}{l}\frac{d \hat{\omega}}{d t} \\ \frac{d \hat{T}_{l}}{d t}\end{array}\right)=\left(\begin{array}{cc}-B / J & -1 / J \\ 0 & 0\end{array}\right)\left(\begin{array}{l}\hat{\omega} \\ \hat{T}_{l}\end{array}\right)+\left(\begin{array}{l}1 / J \\ 0\end{array}\right) T+\left(\begin{array}{l}K_{1} \\ K_{2}\end{array}\right) \operatorname{sgn}(\sigma)$

Where, $\hat{\omega}=$ estimated speed

$\hat{T}_{l}=$ estimated load torque

$\sigma=\omega-\hat{\omega}=e_{\omega}=$ error
For convergence of the observer it is necessary that $K_{2} / K_{1}<0(\mathrm{C} 1)$ and $K_{1}>1 / J\left|e_{T_{l}}\right|_{\max }(\mathrm{C} 2)$. To prove the convergence of the asymptotic observer designed in

equation (24) it can shown that that the error dynamics is given by,

$e_{\omega}=\omega-\hat{\omega}$ And $e_{T_{l}}=T_{l}-T_{\hat{l}}$

Thus, $e \omega=-1 / J e_{T_{l}}-K_{l} \operatorname{sgn}(\sigma)$

And, $e_{T_{l}}=-K_{2} \operatorname{sgn}(\sigma)$

Considering a Lyapunov candidate function,

$V(e)=\frac{1}{2} e_{\omega}^{2}$

Its time derivative along trajectory of $e_{\omega}$ is given as

$V(e)=e_{\omega}\left(-1 / J e_{T_{l}}-K_{1} \operatorname{sgn}(\sigma)\right)$

The observer gains now must be so chosen that

$V(e)$ is negative for convergence to occur. 
So it can be written that,

- If $e_{\omega}>0$, then $K_{l}>-1 / J e_{T_{l}}$

- If $e_{\omega}<0$, then $K_{1}>1 / J e_{T_{l}}$

Since the vector $e_{\omega}(t)$ is bounded for all time' $t$ ' thus establishing the conditions $\mathrm{C} 1$ and $\mathrm{C} 2$.

Consequently $e_{\omega}$ is globally asymptotically stable such that $V(e)<0$ for $e_{\omega} \neq 0$ and $V(e)=0$ when $e_{\omega}=0$. Using the above constraints $\mathrm{C} 1$ and $\mathrm{C} 2$ the observer error thus converges to zero exponentially.

\section{RESULTS}

Simulation was carried out on MATLAB/SIMULINK platform for different load torque disturbance conditions on the developed controller for a $48 \mathrm{~V}, 660 \mathrm{~W}, 3000 \mathrm{rpm}, 8$ pole 3-Phase BLDC motor with specifications as $\mathrm{R}($ Resistance $)=$ 0.100 ohms, L (Inductance) $=0.0003$ Henry, $K_{t}$ (Torque constant $)=0.0455, \quad \mathrm{~K}_{b}($ Back emf Constant $)=0.112$. In accordance with the exponential reaching law approach, the parameters were taken as $\varepsilon=0.5, K=9$.

\section{A. Observer performance}

Using the parameters mentioned above simulation was carried out to test the designed observer for a sequence of load disturbances tracking a speed reference of 300 $\mathrm{rad} / \mathrm{sec}$ and rated load torque of $2.06 \mathrm{~N}-\mathrm{m}$. Initially keeping the value of

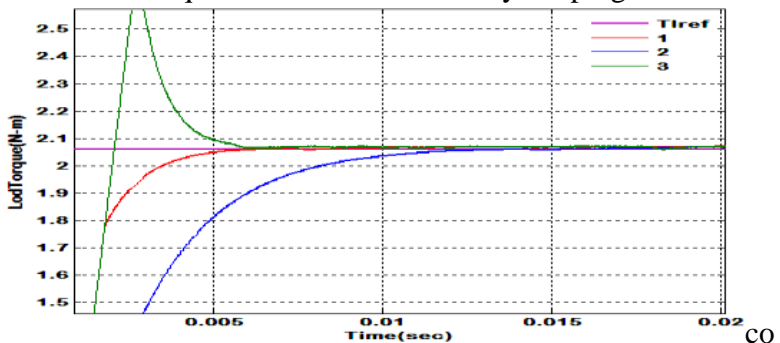

nstant $K_{2}$ w

Fig 3: Observer performance for variation in ' $K_{1}$,

as fixed at -1000 the value of constant $K_{1}$ was varied from 3000 to 10000 satisfying the constraint $\mathrm{C} 1$. The results of the simulation are presented in Fig 3.

In Fig 3 shown above:

'Tlref': Reference load torque of $2.06 \mathrm{~N}-\mathrm{m}$.
1- Observer performance for $K_{1}=5000, K_{2}=-1000$

2- Observer performance for $K_{1}=10000, K_{2}=-1000$

3- Observer performance for $K_{1}=3000, K_{2}=-1000$

Fig 4: Observer performance for variation in ' $K_{2}$ '

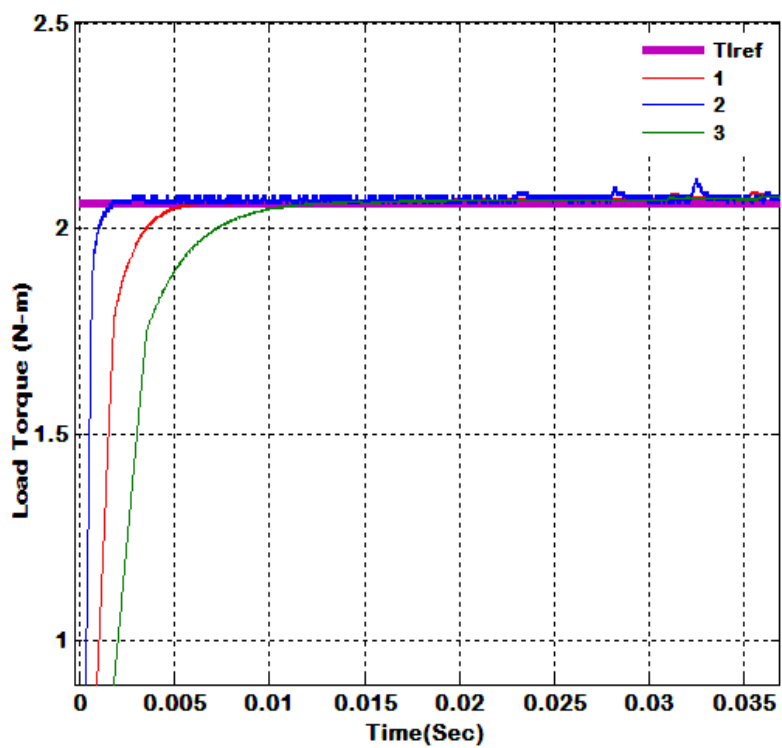

In Fig 4 shown above:

'Tlref': Reference load torque of $2.06 \mathrm{~N}-\mathrm{m}$.

1- Observer performance for $K_{1}=5000, K_{2}=-1000$

2- Observer performance for $K_{1}=5000, K_{2}=-500$

3- Observer performance for $K_{1}=5000, K_{2}=-3000$

On analysis of Fig 3 and Fig 4 it can be concluded that with the increase in values of $K_{1}$ form 3000 to 1000 , the settling time of the observer decreases. However at lower values $K_{1}$ there is an overshoot that would affect the system. With the increase in values of $K_{2}$ from -500 to -3000 the settling time increases while chattering in the designed observer reduces. From the above simulations by choosing $K_{2}=-1000$ and $K_{1}=5000$ the design of the observer was concluded and load tests were carried on. 


\section{B. Testing under load conditions}

The designed controller was tested for a sequence of load torque disturbances varying from $50 \%$ of rated torque to $100 \%$ of rated torque tracking a speed of $300 \mathrm{rad} / \mathrm{sec}$. For simulation purposes the parameters of the controller were kept fixed $\varepsilon=0.5, K=9$ and for the sliding mode torque observer the parameters were fixed at $K_{1}=5000, K_{2}=-1000$. The results of the simulation for the above mentioned parameters are shown in Fig 5.

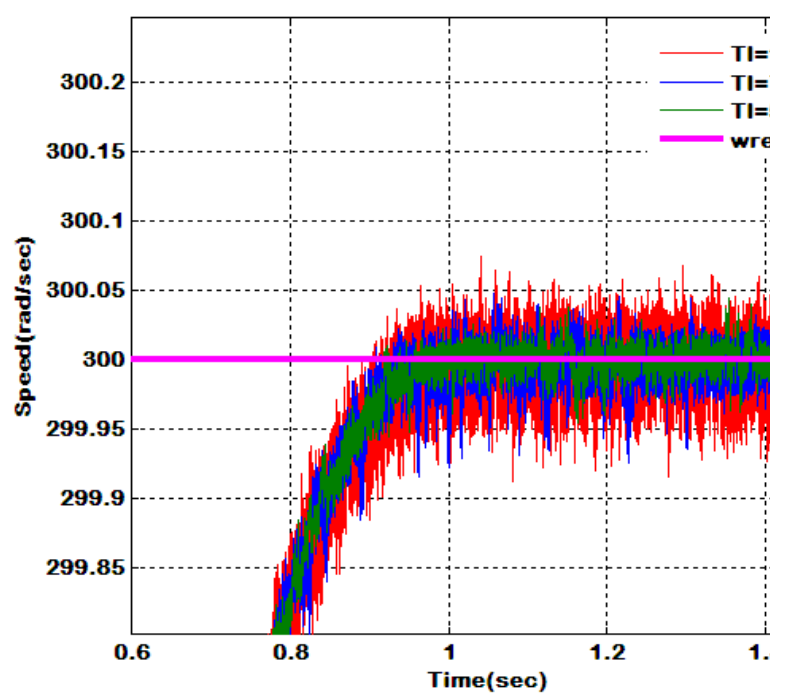

Fig 5: Speed response for variable load torque

It can be concluded from the response obtained from Fig 5 that the designed controller is robust to track the reference speed of $300 \mathrm{rad} / \mathrm{sec}$ successfully under load variations from $50 \%$ of rated load conditions to $100 \%$ of rated load. One notable conclusion that can be drawn is that although with the variation in load the settling time for speed does not change yet the chattering in speed response increases with the increase in load torque. The controller parameters were then varied and their effect on the settling time of the speed response is presented in Fig 6 and Fig 7.

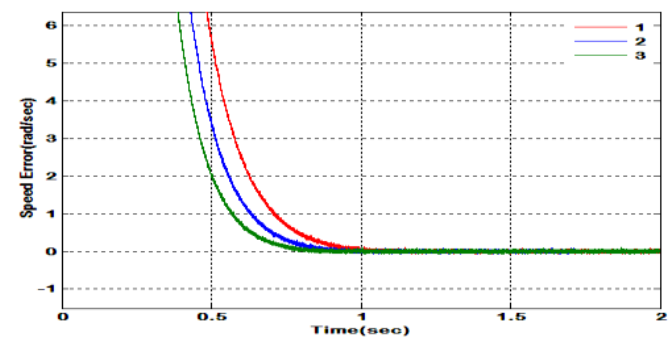

Fig 6: Speed Response for variation in ' $K$ '

In Fig 6:

1- Speed Response for $\mathrm{K}=10, \varepsilon=0.5$
2- Speed Response for $\mathrm{K}=9, \varepsilon=0.5$

3- Speed Response for $\mathrm{K}=8, \varepsilon=0.5$

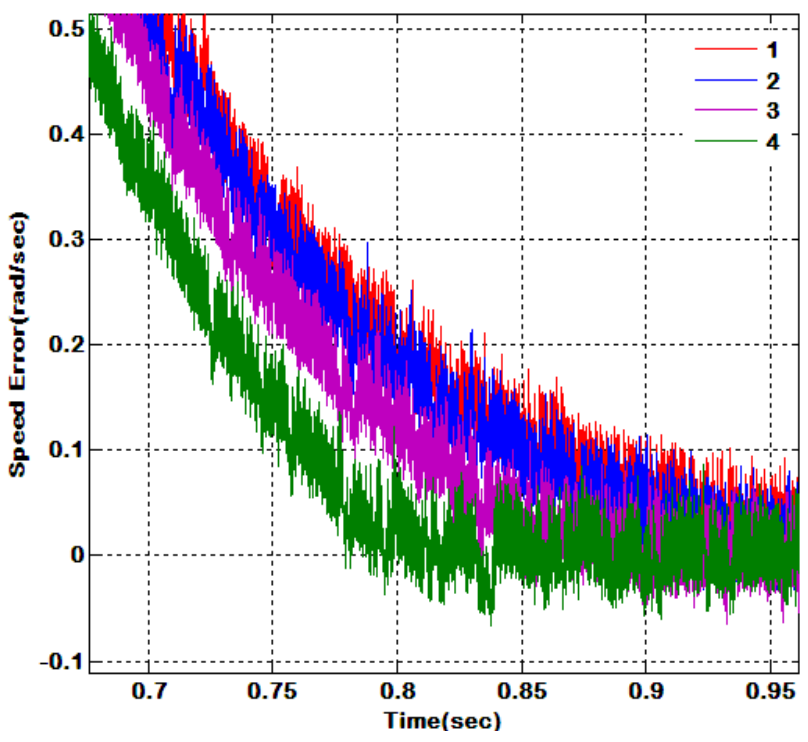

Fig 7: Speed response for variation in ' $\varepsilon$ '

In Fig 7:

1-Speed Response for $\mathrm{K}=9, \varepsilon=0.1$

2-Speed Response for $\mathrm{K}=9, \varepsilon=0.5$

3- Speed Response for $\mathrm{K}=9, \varepsilon=1$

4- Speed Response for $\mathrm{K}=9, \varepsilon=2$

From the Fig 6 and Fig 7 it can be concluded that with the increase in values of parameter ' $\mathrm{K}$ ' the settling time increases while chattering in speed remains constant. The value of ' $K$ ' is not increased further as it directly affects the generated reference currents which exceed the allowable limits. With the increase in values of ' $\varepsilon$ ' from 0.1 to 2 the settling time tends decrease leader to a faster response. The chattering in speed response remains oblivious to the changes in the values of $\boldsymbol{\varepsilon}$. In all the cases the reaching time criterion for the designed controller is satisfied. As per equation (6) the calculated values of the settling time is within the range 14.66 seconds to 2.107 seconds for all the above mentioned parameter combinations. From the simulation results it is seen that that maximum settling time in any case is not more than 1 second. Thus the reaching time criterion is satisfied.

\section{Variable Speed Drive Operation}

After having tested the controller and the observer for a sequence of load torque disturbances, the variable speed response of the controller was tested by subject the system to a random torque sequence as a step response. The observer and controller performance in such a case is shown in Fig 8 and Fig 9 respectively. 


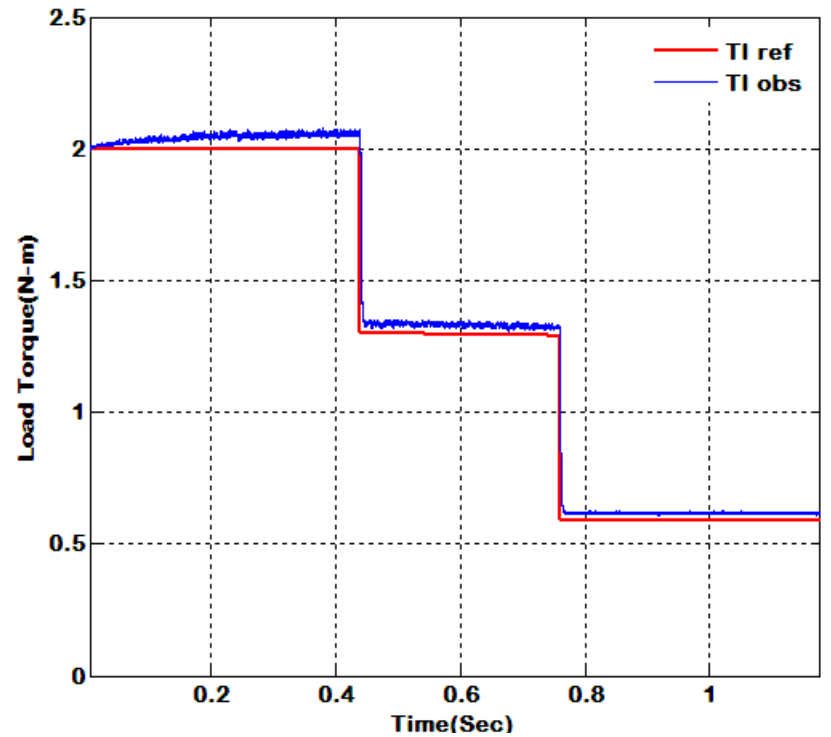

Fig 8: Observer tracking a variable torque change

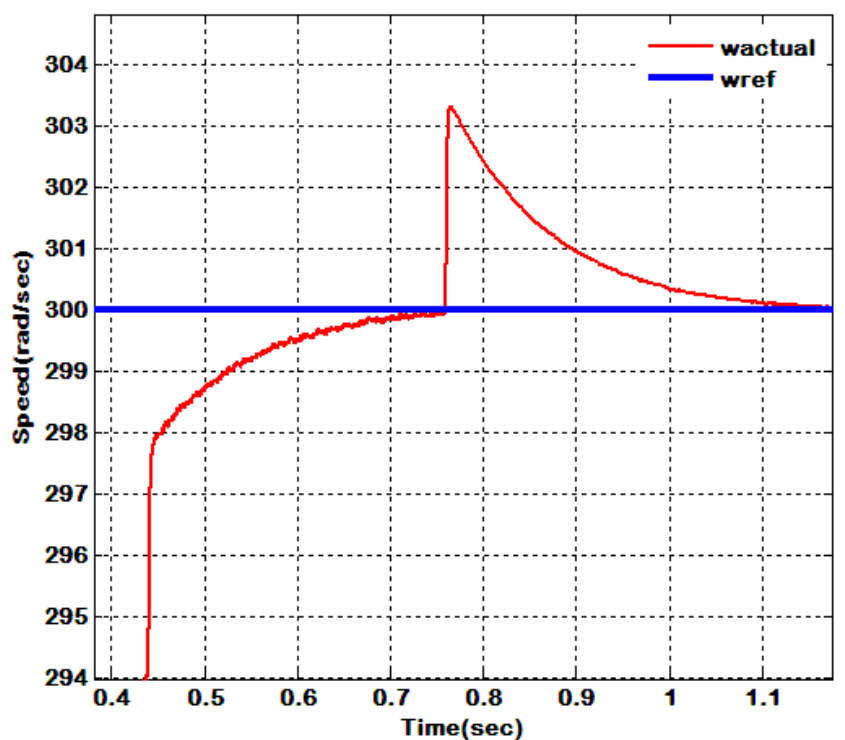

Fig 9: Speed response tracking a variable torque change

From Fig 8 and Fig 9 the effectual response of the observer and the controller when subjected to a random change in load torque is obtained that guarantees the performance of the designed observer-controller pair for the operation of the BLDC drive as a variable speed drive.

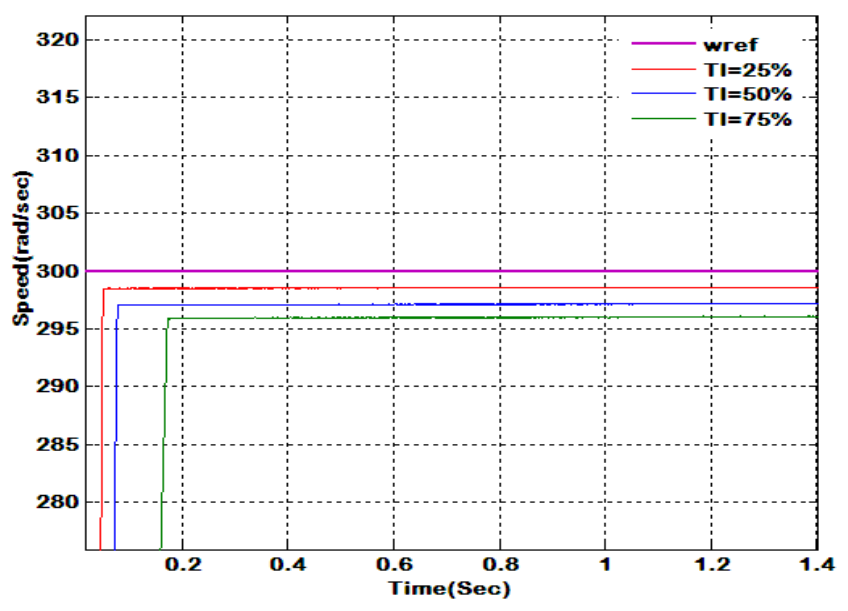

Fig 10: Speed response of PI controller for various load sequences

\section{Comparison between PI-Hysteresis and SMC-Hysteresis}

The performance of the developed SMC- Hysteresis scheme was compared against a PI-Hysteresis and the results were duly noted. The PI controller is of the form $G_{P I}=\left(K_{p}+\frac{K_{i}}{s}\right)$ to control the speed error. By keeping the parameters of $G_{P I}$ fixed at $K_{p}=$ and $K_{i}=0.09$ the scheme was tested for a sequence of load torque disturbances varied from $10 \%$ of rated load conditions to $75 \%$ of rated load conditions. The results of the simulation are presented in Fig 10.

It can be observed from Fig 10 that with the increase in load torque the steady state error in speed increases along with the settling time. With further increase in load torque the system becomes unstable. Comparing this performance with that obtained using SMC based speed controller as shown in Fig 5 it can be concluded that performance of the SMC based scheme is much better. A further comparison between the torque profile of the motor when subjected to load disturbance $75 \%$ of rated capacity between the PI and SMC scheme is shown in Fig 11.

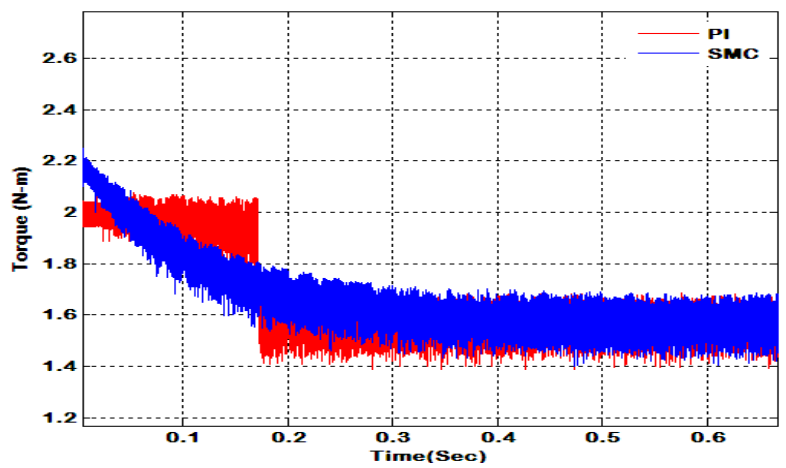

Fig 11: Comparison between torque for PI and SMC 
From Fig 11 it can be concluded that in the PI based control scheme the change in torque is sudden after initial overshoot whereas in the SMC based scheme the transition is smooth. Also the chattering in SMC based scheme is less. It can thus be concluded that for variable drive operation the SMC based controller would be safer bet in comparison to the PI based controller.

\section{CONCLUSION}

In this work an exponential reaching law based SMC based controller was presented to handling load torque disturbances affecting a BLDC drive. To estimate the unknown load torque a sliding mode observer was designed that was effectual in give a fast response even in variable load conditions with a maximum delay of 0.01 seconds. Finally the developed SMC scheme was compared with a PI based speed controller and the advantage of the SMC scheme in relation to handling load disturbances while operating as a variable speed drive is summarized. Finally it was concluded that in chattering persisted in the output response which can be eliminated by employing a low pass filter. In future work the work can be tested on hardware platform by use of fast DSP processors.

\section{REFERENCES}

[1] Padmaraja Yedamale.2003 Brushless DC (BLDC) Motor Fundamentals. Microchip Technology Inc.

[2] Y N Wang,X Z Zhang and X F yuan,2010. Hybrid non-singular terminal sliding mode controller design for electric vehicle system with a brushless dc motor. Proceedings of Institution of Mechanical engineers, Journal of Systems and Control engineering.

[3] Tan Chee Siong, Baharuddin Ismail, Mohd Fayzul Mohammed, Mohd Faridun Naim Tajuddin, Siti Rafidah Abd. Rahim, Zainuddin Mat Isa, 2010. Study of Fuzzy and PI controller for Permanent-Magnet Brushless DC motor drive. In Power Engineering and Optimization conference.

[4] Yan Xiaojuan, Liu Jinglin ,2010. A Novel Sliding Mode Control for BLDC Network Control System. In $3^{\text {rc }}$ International Conference on Advanced Computer Theory and Engineering.

[5] Mehdi Nasri, Hossein Nezamabadi-pour, and Malihe Maghfoori, A PSO-Based Optimum Design of PID Controller for a Linear Brushless DC Motor. World Academy of Science, Engineering and Technology 262007.

[6] Utkin V.I, 1993. Sliding mode control design principles and applications to electric drives. In Industrial electronics, IEEE transactions.

[7] P.C.Sen, Comparative Study of proportional-Integral, Sliding Mode and Fuzzy Controllers for power converters, Industry Applications Conference, 1995.

[8] Weibing Gao,1993.Variable Structure Control of Nonlinear Systems: A New Approach, IEEE transactions on Industrial Electronics, VOL 40.No.1.

[9] James Mentz. Rejection of an Unknown Torque Load disturbance on a Brushless DC Motor. Virginia Tech.

[10] B.Bandyopadhyay, F. Deepak and Kyung-Soo Kim.2009. Sliding Mode Control Using Novel Sliding Surfaces, Springer.

[11] Slotine.J.J.E and Li. W.1991. Applied Nonlinear Control, Prentice-Hall.

[12] W.Santungtong and S.Sujitjom,2006. "Adaptive slidingmode speed torque observer. In WSEAS Transactions on Systems, Vol 5 no 3,pp458-466,March. 